\title{
Rediscovery of Coelostoma thienemanni (Coleoptera: Hydrophilidae): the first record from continental Asia and correction of its subgeneric assignment
}

\author{
Martin Fikáček ${ }^{1^{*}}$, Andre Skale ${ }^{2}$ \& Feng-Long Jia ${ }^{3}$ \\ ${ }^{1}$ National Museum, Department of Entomology, Cirkusová 1740, CZ-193 00, Praha 9, Czech Republic; \\ mfikacek@gmail.com \\ ${ }^{2}$ Wilhelm Kohlhoff Str. 3, 95032 Hof, Germany \\ ${ }^{3}$ Institute of Entomology, Sun Yat-sen University, Guangzhou, 510275, Guangdong, China; \\ Issjfl@mail.sysu.edu.cn \\ * corresponding author
}

Fikáček M., Skale A. \& Jia F.-L., 2019: Rediscovery of Coelostoma thienemanni (Coleoptera: Hydrophilidae): the first record from continental Asia and correction of its subgeneric assignment. - Journal of the National Museum (Prague), Natural History Series 188: 89-94.

\begin{abstract}
We are reporting a recent discovery of Coelostoma (Lachnocoelostoma) thienemanni Orchymont, 1932 (Coleoptera: Hydrophilidae: Sphaeridiinae: Coelostomatini) from northern Vietnam, which represents the first record of the species since 1929 and its first record from continental Asia. The species is redescribed and illustrated, and transferred from the subgenus Holocoelostoma Mouchamps, 1958 to Lachnocoelostoma Mouchamps, 1958. The species is unusual among Asian Coelostoma by its complex three-dimensional shape of the median lobe of the aedeagus, in which it is only similar to C. tangliangi Jia et al., 2017 in Asia. The species is also unusual by its very long dorsal tarsal swimming hairs, indicating that it is an aquatic species.
\end{abstract}

Keywords: water scavenger beetles, Sphaeridiinae, Coelostomatini, Vietnam, Oriental Region

Received: August 24, 2018| Accepted: November 24, 2018 | Issued: December 13, 2019

\section{Introduction}

The genus Coelostoma Brullé, 1835 is one of the most abundant genera of the hydrophilid subfamily Sphaeridiinae, at the moment comprising 111 described species (Short \& Fikáček 2011; Jia et al. 2014, 2017), and containing many undescribed ones. It is distributed in the Old World only, with the highest species diversity known from tropical Africa and Asia. Recently, the genus was taxonomically studied and revised in China and close surroundings (Jia et al. $2014,2017)$, and a revision of the species of the Indian subcontinent is under preparation as well (Sheth et al., unpubl. data). 
Coelostoma species are externally very uniform, and only very few characters may be used as diagnostic for subgeneric placement (setation of meso- and metafemora, presence/ absence of stout setae on the abdominal apex; Mouchamps 1958, Jia et al. 2014) or for species identification (presence/absence of serially arranged punctures at sides of elytra, shape of the prosternum and of the abdominal apex, density and size of dorsal punctation and body size; Jia et al. 2014, 2017). Reliable species identification is however only possible based on male genitalia, which are very diverse morphologically and provide usually easyto-observe diagnostic characters. Recently, Jia et al. (2017) described the first Asian species of the subgenus Lachnocoelostoma, C. tangliangi Jia et al., 2017 from Hainan Island, with very complex morphology of the median lobe, which is three-dimensional and resembles the bottle opener in shape. In 2015, the second author of this contribution collected another species of Lachnocoelostoma with this kind of the median lobe in northern Vietnam; we originally considered this species undescribed. A review of literature revealed that it may stand close to the Sumatran C. thienemanni which was however assigned to a different subgenus, Holocoelostoma Mouchamps, 1958, by Hansen (1999). Reexamination of the type series of the latter species proved the Vietnam specimen as conspecific, and indicated the incorrect subgeneric placement of $C$. thienemanni. The species is redescribed and illustrated here and its subgeneric assignment is corrected. It is already the second species originally considered as endemic to Malay Archipelago which was recently found in continental Asia, the first being $C$. subditum Orchymont, 1936 originally described from Borneo and recently found in China (Jia et al. 2017).

\section{Material and methods}

The newly collected specimen was dissected, and its genitalia and the abdominal apex were photographed in glycerine jelly using a Canon D1100 digital camera attached to an Olympus BX41 compound microscope. Habitus photographs and details of external morphology were taken using Canon D-550 digital camera with attached Canon MP-E65mm f/2.8 1-5 macro lens. Photographs with different focus level were combined into the final ones with Helicon Focus software. Type specimens, and an additional specimen from Nias, were examined in dry condition (including the dry-mounted genitalia of the Nias specimen) and photographed in the same way as the habitus of the Vietnam specimen.

Morphological terminology and systematics follows Jia et al. (2014, 2017). Examined specimens are deposited in the following collections:

BMNH Natural History Museum, London, United Kingdom (M. Barclay, M. Geiser, K. Matsumoto);

IRSNB Institute Royal des Sciences Naturelles de Belgique, Brussels, Belgium (P. Limbourg);

NMPC National Museum, Prague, Czech Republic (L. Sekerka, J. Hájek, M. Fikáček).

The comparison with Coelostoma tangliangi is based on the paratype specimen of the latter species deposited in NMPC.

\section{Taxonomy}

\section{Coelostoma (Lachnocoelostoma) thienemanni Orchymont, 1932}

(Figs 1-15)

Coelostoma Thienemanni Orchymont, 1932: 672, Fig. 39.

Coelostoma (Holocoelostoma) thienemanni: Hansen (1999: 248).

Type material examined. Syntypes ( 1 male, 3 females): 1 male with dissected but lost genitalia (IRSNB): 'SUMATRA Da. Ranaoe / Abfluss: schwimm. Baumstamm [= outlet: 

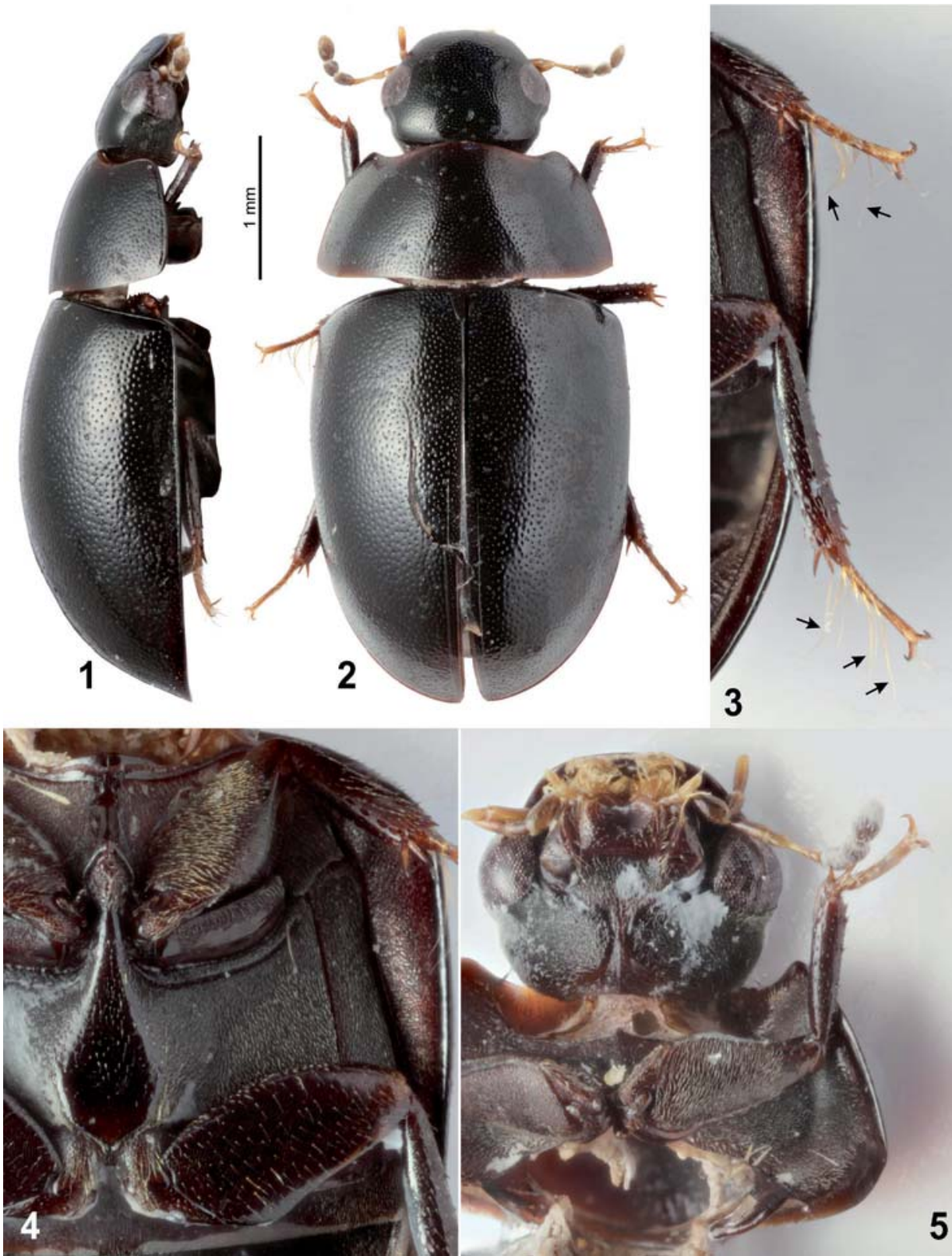

Figs 1-5. Coelostoma (Lachnocoelostoma) thienemanni Orchymont, 1932, specimen from Vietnam: 1) dorsal view, 2) lateral view, 3) meso- and metatarsi with long dorsal swimming hairs, 4) meso- and metaventrite and femora, 5) head, prothorax and prothoracic leg in ventral view.

floating tree trunk] / 15129 [= 15.i.1929] / Exp. Thienemann / [reverse side of the label] (62) FR5c // FR5c 25/1 // Thienemanni / Pas de car. Ventr. / Tarses courts // TYPE'; 2 females (IRSNB): 'SUMATRA Da. Ranaoe / Abfluss: schwimm. Baumstamm [= outlet: floating tree trunk] / 15129 [= 15.i.1929] / Exp. Thienemann / [ventral side of the label] (62) FR5c 
// FR5c 25/1 // Para- / type'; 1 female (IRSNB): SUMATRA Da. Ranaoe / Ausfluss überschw. Ufer [= outlet, flooded bank] / 25129 [= 25.i.1929] / Exp. Thienemann / [reverse side of the label] (50) R1a'.

Additional material examined. INDONESIA: Nias: 1 male (BMNH): ‘58162 // Sumatra / Nias // Fry Coll. / 1905100 // German / Mission // Knisch det. 1926 / Coelostoma / horni / Rég. // Coelostoma (ab.) / thienemanni d'Orch. / Balfour-Browne det.'. VIETNAM: Ninh Binh: 1 male (NMPC): 'N-VIETNAM, Ninh Binh Prov. / Cuc Phuong NP, N20¹7.572'N / $105^{\circ} 40.052 ', 270 \mathrm{~m}, 22.5$. - / 24. 5. 2015, leg. A. Skale'.

Redescription. Form and Color. Body length 4.2-4.8 mm, body width 2.6-3.0 mm. Body oval, moderately convex. Dorsum black, pronotum with brownish margins. Labrum, maxillary and labial palpi and antennomeres 1-6 yellowish to reddish brown, antennal club slightly darker, brown. Ventral surface brown to dark brown; femora and tibiae dark reddish brown, tarsi pale reddish.

Head. Dorsal surface with dense and moderately coarse punctures. Intervals between punctures smooth. Clypeus truncate anteriorly. Eyes large, separated by ca. $3.3 \times$ the width of one eye, weakly emarginate anteriorly. Mentum ca. $1.7 \times$ wider than long, bisinuate on anterior margin, strongly depressed anteromesally, depressed part without punctures; posterior and lateral parts with moderately large sparse setiferous punctation; interstices smooth, without microsculpture. Gula very narrow, carinate medially, finely microsculptured. Antenna with 9 antennomeres, antennal club loosely segmented.

Thorax. Pronotum with dense and moderately coarse punctures, similar to punctation of head; lateral marginal bead nearly reaching posterior corner, not continuing to posterior margin. Prosternum very weakly carinate posteromesally, anteromesally with strongly elevated ridge. Mesoventrite with raised, arrowhead-shaped process, ca. $1.3 \times$ longer than wide, surface with sparse punctation bearing long setae. Metaventrite ca. $3.4 \times$ longer than mesoventral elevation, with strongly raised median portion broadly projecting anteriorly between mesocoxae and abutted to mesoventral process; lateral portions of metaventrite densely microsculptured and pubescent, middle portion bare, with very sparse pubescence. Metepisterna $5.7 \times$ as long as wide, parallel-sided. Scutellar shield slightly longer than wide, with punctation as on pronotum. Elytra with punctation coarse, similar to that on pronotum, lateral parts of elytra with punctation similar as near suture, without apparently coarser or subserially arranged punctures; sutural stria reaching anterior third of elytral length. Profemora densely pubescent ventrally in basal three-quarters; mesofemora with dense pubescence intermixed with stout setae in basal four-fifths; metafemora with very sparse and fine punctation, each puncture with a long seta, interstices with fine transverse microsculpture. Meso- and metatarsi with very long dorsal (natatory) setae and shorter dense ventral setae; protarsus with longer ventral setae only. Claws evenly curved, without basal additional tooth.

Abdomen. Abdominal ventrites densely pubescent. First abdominal ventrite without median carina; last ventrite with shallow median emargination fringed with row of stout setae apically.

Aedeagus. $1.18 \mathrm{~mm}$ long. Median lobe strongly sclerotized, shorter than parameres, and ca. as wide as each paramere basally; deeply excavated in lateral view (bottle-opener-shaped), the excavation delimited by deeply bilobed dorsal projection of median lobe and the dorsally bent apex of median lobe; gonopore situated apically. Parameres narrowing from base to apex, very narrow subapically (Figs 6-9).

Biology. The type series was collected on flooded bank of the lake and from the floating tree trunks on the same lake; collecting circumstances of the additional two specimens are unknown. Based on these data, the species seems to be aquatic, inhabiting standing waters. The very strongly developed dorsal tarsal swimming hairs indicate that the species is a good swimmer. 


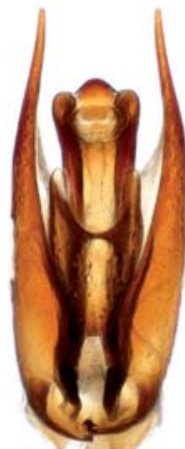

6

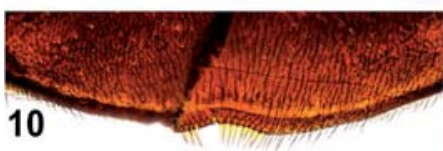

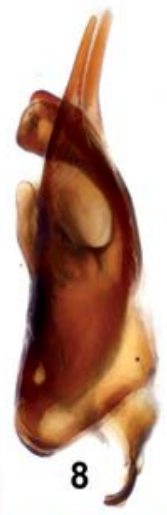
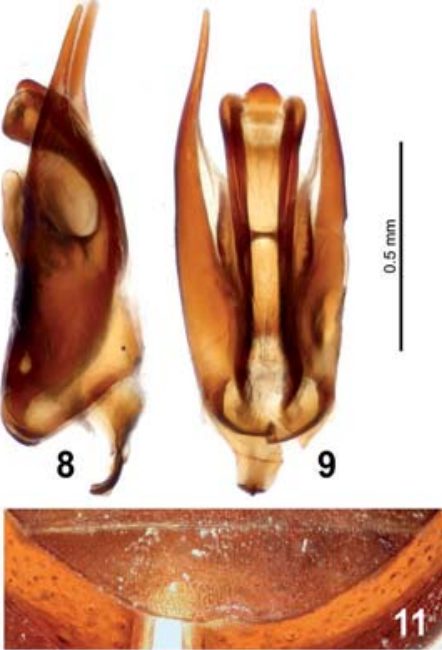

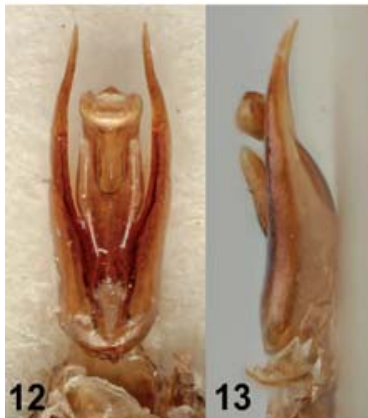

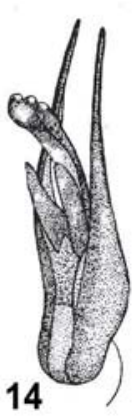

14

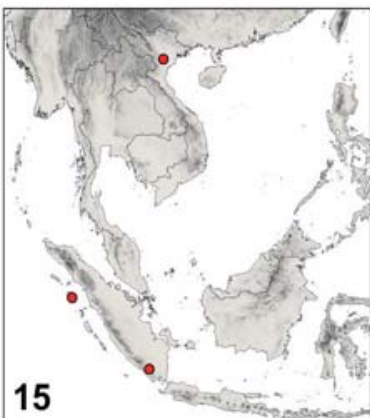

15
Differe $n$ t i a l diagnosis. $\quad \mathrm{By}$ genital morphology, C. thienemmani sp. nov. only resembles C. tangliangi Jia et al., 2017 from Hainan Island, China, by the complex threedimensional shape of the median lobe resembling the bottle opener (see Jia et al. 2017, Figs 1-4). In contrast to C. tangliangi, the species has much narrower median lobe with the dorsal shorter projection forming two separate 'fingers' (this part of only slightly bilobate in C. tangliangi), and very narrow apical portion of the parameres (widely expanded in C. tangliangi). Externally, $\quad C$. thienemmani bears coarser punctation of pronotum and elytra than C. tangliangi. Co e l o s to $\mathrm{ma}$ thienemanni is also characterized by a shallow emargination on the abdominal apex (Figs 10-11), in which it is the unique among Asian Coelostoma; all other species including $C$. tangliangi have evenly arcuate posterior margin of abdominal ventrite. Coelostoma thienemanni is also characterized by many very long dorsal swimming hairs on meso- and metatarsi (Fig. 3), which is only found in some Asian Coelostoma, namely in C. tangliangi and the species characterized by very large aedeagi with very long apically spatulate parameres and the median lobe with complex apical structure (i.e. the group consisting of $C$. parkeri, $C$. phallicum, $C$. vagum and $C$. wui); in all these species, the setae are however much sparser than in $C$. thienemanni.

Distribution. Known from three widely distant localities: southern Sumatra, Nias island and northern Vietnam (Fig. 15).

Remarks. The aedeagus of the only male syntype illustrated by Orchymont (1932; Fig. 14) is unfortunately lost. The illustration agrees well with the genitalia of the specimen from Nias in all visible details including the slightly pointed shape of the ventral 'fingers' of the 
median lobe (compare Figs 13 and 14). In the specimen from Vietnam, these 'fingers' are blunt apically in lateral view, and seem to be slightly more separated from each other than in the Nias specimen. The Vietnam specimen also seems to have slightly more elongate body, but this may be caused by the fact that it is broken between pro- and mesothorax, and hence more extended. All other characters examined are identical between the Sumatra, Nias and Vietnam specimens, including the coarse dorsal punctation, long tarsal swimming hairs and emarginate abdominal apex, i.e. characters which are uncommon among Asian Coelostoma. We hence consider all examined specimens conspecific, and the small observed differences as artifacts (dry versus wet condition of the aedeagus, complete and convolved body versus partly broken and hence more extended body).

Subgeneric assignment. Coelostoma thienemanni was described without being assigned to any subgenus, as these were only introduced by Orchymont (1940) and Mouchamps (1958). Coelostoma thienemanni is however not mentioned in the latter papers and stayed unassigned to subgenus until Hansen (1999: 248) placed it to Holocoelostoma Mouchamps, 1958 in the catalogue of the Coelostoma species. The reasons for this subgeneric assignment were not explained, and contradict the characters provided by Orchymont (1932) in the original description, i.e. densely pubescent mesofemora and abdominal apex with stout setae, which clearly assign $C$. thienemanni to the subgenus Lachnocoelostoma. We are here confirming the presence of these diagnostic characters in C. thienemanni (Figs 4, 10-11) and transfer the species to Lachnocoelostoma accordingly.

\section{Acknowledgements}

We are indebted to P. Limbourg (IRSNB) and K. Matsumoto and M. Geiser (BMNH) to allow the visit of MF to the Brussel and London collections in November 2018. We are obliged to Dr. Hong Thai Pham (Head of Specimen Collections Management Department, Academy of Science and Technologie, Vietnam National Museum of Nature) for the invaluable support, especially during the second author's excursions in 2013 and 2015. The work of M. Fikáček was supported by the Ministry of Culture of the Czech Republic (DKRVO 2019-2023/5.I.a, National Museum, 00023272); the work of F.-L. Jia was supported by the National Natural Science Foundation Of China (31772494).

\section{References}

Hansen M., 1999: World Catalogue of Insects. Volume 2. Hydrophiloidea (s.str.) (Coleoptera). Stenstrup: Apollo Books: 416 pp.

Jia F.-L., Aston P. \& Fikáček M., 2014: Review of the Chinese species of the genus Coelostoma Brullé, 1835 (Colleoptera: Hydrophilidae: Sphaeridiinae). - Zootaxa 3887, 3: 354-376.

Jia F.-L., Lin R.-C., Chan E., Skale A. \& Fikáček M., 2017: Two new species of Coelostoma Brullé, 1835 from China and additional faunistic records of the genus from the Oriental Region (Coleoptera: Hydrophilidae: Sphaeridiinae: Coelostomatini). - Zootaxa 4232, 1: 113-122. https://doi.org/10.11646/zootaxa.4232.1.8

Mouchamps R., 1958: Notes sur quelques Coelostoma (Brulle) (Coleopteres Hydrophilidae) principalment africains (12 ${ }^{\mathrm{me}}$ note). - Bulletin de l'Institut Royal des Sciences Naturelles de Belgique 34, 41: 1-36.

Orchymont A. d', 1932: Zur Kenntnis der Kolbenwasserkäfer (Palpicornia) von Sumatra, Java und Bali. - Archiv für Hydrobiologie, Supplement Band IX (Tropische Binnenwässer II): 623-714 + pls XIV-XVII.

Orchymont A. d', 1940: Contribution à l'étude des Palpicornia XIV. - Bulletin et Annales de la Socitété Entomologique de Belgique 80: 157-197.

Short A.E. Z. \& Fikáček M., 2011: World Catalogue of the Hydrophiloidea (Coleoptera): additions and corrections II (2006-2011). - Acta Musei Nationalis Pragae 51, 1: 83-122. 